\title{
Motivational Factors
}

\section{${ }^{1}$ Sapna Singh, ${ }^{2}$ Deepak Kumar}

\begin{abstract}
As in my opinion each employee is different rather each individual is different. In this paper I have categorized employees in three parts according to their needs and behavior and have set different motivational factors for each type. Like American psychologist, Abraham Maslow gave his Hierarchy of needs model, he has suggested that human has five level of needs. Given below is the pyramid of needs by Maslow:
\end{abstract}

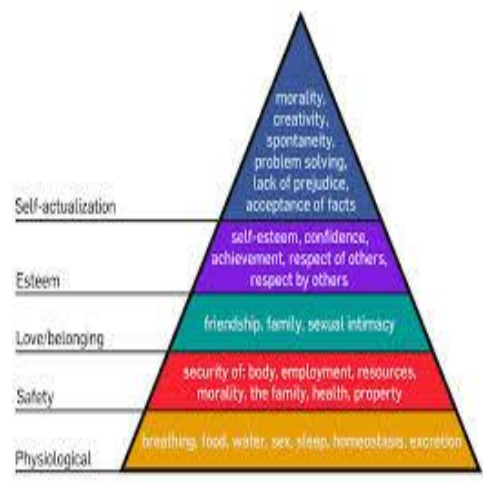

Fig 1

Maslow argued that people try to satisfy their lower order needs before their higher level needs [2]. Therefore, each employee falls in different level of needs in my opinion and needs are responsible for different behavior and attributes of employees and thus leader has to act differently in order to meet individual's needs. Therefore, the motivational factors for different employees should be different. I have emphasized on the fact that different set of motivational factors work for different employee in this paper and categorized employees in three different types but I would also like to emphasize on the fact that leader should not differentiate between his employees as clearly stated in Equity theory of motivation, developed in the early 1960's by J. Stacey Adams, motivation can be affected through an individual's perception of fair treatment in social exchanges. When compared to other people, individuals want to be compensated fairly for their contributions (the outcomes they experience match their inputs). A person's beliefs in regards to what is fair and what is not fair can affect their motivation, attitudes, and behaviors [3]. So to be clear with my approach of motivational factors with three types of employees, I would like to state as precautionary measure that leader has to execute each motivational factor for all but keeping each type of employee in mind. We have also included definition of leadership in this paper by some great people so that readers can understand real meaning of leadership.[3]

\section{Introduction:}

Let us first try to understand what is "Motivation"? And why "motivational factors" are so important for growth and development of an employee and organization? In beautiful words of Dwight D Eisenhower "Motivation is the art of getting people do what you want to do because they want to do it". Motivation in my words is the factor or factors which keep you enthusiastic and committed to your work or job. Also, Motivation can be defined as the force that energies behavior, gives direction to behavior and underlies the tendency to persist even in the face of one of more obstacles [4]. Motivated people voluntarily and enthusiastically do more than what is required. It can be as intentional or directional, Intentional- it refers to personal choice and Directional- presence of a driving force aimed at attaining a specific goal [11]. Let me add one more definition by Stephen P Robins in this context -"Motivation is the willingness to exert high levels of effort towards organization goals conditioned by the effort's ability to satisfy some individual need ". A leader thus strives to meet the employee's important needs or basic requirements to get better results and productivity. As the workforce becomes more diverse, recognizing the individual needs becomes very difficult and a lot of time is required to know and observe the employees behavior. Motivational factors are so important for leader to get the work done from his people effectively and in turn keep them vitalize.

Leaders play the most important role in motivation of employees so it is very important to talk about leadership and leaders. Though leadership is the world's oldest and complex issue, let us put some efforts to understand some aspects of leaders and leadership. PJ Smit and GJ DE Cronje in their book of management principles stated "Leadership is the activity that infuses energy into the organization to activate its members and 
resources to get things moving and keep them in motion." Leadership can also be defined as influencing and directing the behavior of individuals and groups in such a way that they work willingly to pursue the objectives and goals in the organization [2]. Few people have an opinion that leadership is a trait and few people are born with trait of leadership, intelligence, perseverance and ambition, like trait approach to leadership - This style of leadership gives more credence to the qualities a person is born with rather than what they develop or the relationships they develop with followers. Leadership trait theory is the idea that people are born with certain character traits. This is the style that is attributed to a leader who others see as "a born leader". The innate qualities and characteristics possessed by strong leaders. These traits, while not totally responsible for an individual's success as a leader, are influential in the success of the leader. This theory assumes that if you could identify people with the correct traits, you will be able to identify leaders [5]. However, Jack Welch says "Leadership can be found in anyone as long as they contribute, come up with good ideas, and can energize, excite and inspire rather than enervate, depress and control."[6]

When it comes to leadership I have the same opinion as of Fiedler's contingency theory of leadership (It is based on the assumption that for lack of single best style, successful leadership depends on the fit with regard to the leader, the subordinate and the situation. In short, leader's effectiveness is determined by how well his or her style fits the situation. A leader should analyze the situation and understand which style fits the best on the situation [2]. Similarly, leader should analyze the work and behavior of each person of his team and set the motivation factor accordingly. As leader is one who knows and shows the path to his people. Leadership behavior or styles tend to vary considerably from situation to situation. While the behavior of some leaders is characterized mainly by directing their followers, activities in terms of task accomplishment, other leaders concentrate on providing socio emotional support and building personal relationships between themselves and their followers. In other situations, various combinations of directive and supportive behavior are evident. This approach to leadership is referred to as situational leadership, meaning that leader changes his or her style according to the situation and unique demands of a particular situation [8]. In my paper, I would like to put forward the same perspective that leader could not act in same way in every situation and with every member of his team as each individual has different needs and goals. Also, the theory Hersey and Blanchard's situation leadership theory have the same approach that leaders should match their leadership style to the development level of the person, or people, being led. As the name implies, leadership depends upon each individual situation and no single leadership style can be considered best [9].

A leader needs sound insight into abilities, skills perception, attributes and personalities in attempting to motivate people. Like in mid 1960' Edwin A Locke explained in his Goal setting theory stated people are motivated when they participate in setting challenging goals for themselves, understand their role in achieving those goals, and progress is measurable [7].

Motivation is a complex phenomenon. Several theories attempt to explain how motivation works. Frederick Herzberg offers another framework for understanding the motivational implications of work environments [10]. By introducing motivational factors and hygiene factors, Frederick want to stress that if company want real satisfaction for his employees they have to work on their policies, remuneration, Appraisal system and working condition.

From Herzberg's theory of motivation it can be argued that changing pay would not directly motivate an individual but if pay is inadequate or mismatch with employee needs, dissatisfaction and to achieve satisfaction, it is very important to avoid dissatisfaction. As Herzberg argues that hygiene factors if neglected, can make an employee dissatisfied but good pay, pleasant working conditions and others do not contribute significantly job satisfaction and performance. Economic dimension is the most basic in any employment relationship. For an individual employee, the compensation gained form an employment relationship provides the means to satisfy many needs from very basic one such as food and shelter to those achievement status, power and self esteem. Money then motivates to the extent that it is seen by an employee as means of purchasing that which he or she wants. [8]. Therefore, I have added awards, monetary benefits as motivational factors in my approach.

\section{My Approach:}

Keeping in mind above definitions and different need theories, we have come up with some motivational factors for first line employees of corporate. Since every individual is different, I have categorized the employees into three different types.

\begin{tabular}{|l|l|l|}
\hline Type 1 & Type 2 & Type 3 \\
\hline $\begin{array}{l}\text { There are few employees who } \\
\text { themselves are committed to their } \\
\text { work and work for self satisfaction. }\end{array}$ & $\begin{array}{l}\text { There are few employees who themselves } \\
\text { are not committed so much to their work } \\
\text { and work to fulfill their needs for example } \\
\text { Monetary. }\end{array}$ & $\begin{array}{l}\text { There are few employees who pretend to } \\
\text { work and try to be in the good books of their } \\
\text { leaders. They use their team members or } \\
\text { colleagues to achieve their targets. }\end{array}$ \\
\hline
\end{tabular}




\section{Motivational ways for:}

Type 1

- Such type of employees should be treated differently; leaders should act as a guide to help them improve their work through personal interaction, praises and rewards.

- They should be rewarded and rewards could be recognition awards like bonus points, employee of the month award.

- Leader should conduct one to one meeting with each employee of his group. So, that he can understand their goals and work accordingly and help them grow in the organization.

- Increment in salaries annually, half yearly and appraisals.

Type 2

- Such type of employees should be motivated by leaders at short intervals of time.

- They should also be rewarded by leaders by Increment in salaries yearly or half yearly (depending on companies policy)

- They should be given daily or weekly targets as such type of employees will work hard if monitored closely.

- There should be some monetary variable in salary which should be based on performance. Type 3

- For such type of employees their work should be closely Quality check (QC) and leaders should interact with other members of the team on monthly basis and himself monitor his/her activities to find out if an employee is using team members to achieve his targets.

- He should be alarmed by the leader.

- Leader should understand where this person is lacking and his shortcoming so that he can be trained accordingly.

Also, an employee should be motivated to do right things to achieve his set goals in following ways:

- Innovation award should be introduced for the team members so he is motivated to do something on his own.

- Out of the box thinking award should be introduced: - this will compel an employee to be self dependent.

\section{Conclusion}

To conclude, We would like to say that If each employee is motivated considering the fact that every individual needs are different then each employee can do wonders for an organization and can take the organization to next level thus improving the future of next generation. Leader should not only analyze situation but behavior and need of his people and set different set of motivational factors for them as rightly said by Sam Walton- "Outstanding leaders go out of their way to boost the self esteem of their personnel. If people believe in themselves, it's amazing what they can accomplish." Also, in the paper we have tried to specifically categorized employee type and have suggested motivational factor that can play an important role not in life of an individual as well as for the organization. It will also help leaders in their as well as organizational development.

\section{References:}

[1]. http://personalityspirituality.net/articles/the-hierarchy-of-human-needs-maslows-model-of-motivation/

[2]. Management Principles 2nd edition by PJ Smit \& GJ DE JCronje (page 293 and page 279)

[3]. https://wikispaces.psu.edu/display/PSYCH484/5.+Equity+Theory

[4]. HRM in SA (second edition) by Grobler, Warnich, Carrel and Hatfied (pg 105)

[5]. https://sites.google.com/a/stgregoryschool.org/mr-roberts/home/theoretical-and-applied-leadership/trait-approach-leadership

[6]. http://advice.vietnamworks.com/en/hiring/effective-management/twelve-lessons-jack-welch-s-leadership-style.html-0

[7]. http://www.csi-international-inc.com/experience-exchange-blog/employee-engagement-motivation.html

[8]. Introduction to Human Resources Management by Marius Meyer \& Monica Kristen.(page101 and page 103)

[9]. http://www.leadership-central.com/situational-leadership-theory.html

[10]. http://www.cliffsnotes.com/more-subjects/principles-of-management/motivating-and-rewarding-employees/motivation-theoriesindividual-needs

[11]. Human Resource Management 7th Edition by NEL WERNER HAAS BROEK POISAT SONO SCHULTZ (page 361) 